\title{
ANALISIS POTENSI ENERGI TERBARUKAN LIMBAH KOTORAN DARI TERNAK SAPI DI KECAMATAN KUSAMBI KABUPATEN MUNA BARAT PROVINSI SULAWESI TENGGARA
}

\author{
Sutrianto ${ }^{1}$, Achmad S.Aku ${ }^{2}$ dan Muh. Amrullah Pagala ${ }^{2}$ \\ ${ }^{1)}$ Alumnus Fakultas Peternakan Universitas Halu Oleo \\ ${ }^{2)}$ Staf Pengajar Fakultas Peternakan Universitas Halu Oleo \\ e-mail : surya_sutrianto@yahoo.com
}

\begin{abstract}
Abstrak
Penelitian ini bertujuan untuk mengetahui pemanfaatan limbah ternak sapi, potensi energi terbarukan dari limbah ternak sapi di Kecamatan Kusambi Kabupaten Muna Barat. Data yang digunakan dalam penelitian ini adalah jenis data primer, yang terdiri dari 72 responden. Selanjutnya dilakukan analisis deskriptif dan analisis konversi kotoran ternak menjadi gas methan. Hasil penelitian menunjukkan bahwa limbah ternak sapi (feses) yang ada di Kecamatan Kusambi Kabupaten Muna Barat belum termanfaatkan karena kurangnya pengetahuan yang dimiliki oleh peternak tersebut untuk pemanfaatan limbah ternak sapi sebagai pupuk kompos/pupuk organik. Potensi energi terbarukan dari limbah ternak sapi sebesar $5.080 \mathrm{Kg}$ feses/hari atau setara dengan 98.640,78 $\mathrm{m}^{3}$ gas dengan kandungan methan sebesar $69.048,54 \mathrm{~m}^{3}$.
\end{abstract}

Kata kunci: ternak sapi, limbah, pupuk, biogas

\begin{abstract}
This study was aimed to examine the usage of cattle waste, potential renewable energy in Kusambi Regency, West Muna. Data used in this study was primary data, which consists of 72 respondents. Furthermore, the data was analyzed using descriptive analysis and analysis of cattle feces conversion into methane gas. The result showed that cattle feces in kusambi, West Muna, had not been used optimally, due to lack of knowledge about how to use cattle waste as compost/organic fertilizer. Renewable potential energy of cattle feces is $5.080 \mathrm{Kg} /$ day, equals to $98.640,78 \mathrm{~m}^{3}$ of gas which is contained $69.048,54 \mathrm{~m}^{3}$ of methan.
\end{abstract}

Keywords : cattle, manure, fertilizer, biogas.

\section{PENDAHULUAN}

Mempertahankan keamanan pasokan energi dalam jangka panjang merupakan tugas dan tanggung jawab pemerintah, terutama dalam hal pasokan minyak bumi untuk me menuhi kebutuhan energi nasional. Fakta menunjukkan bahwa di Indonesia telah terjadi kekurangan kebutuhan pasokan minyak yang diakibatkan karena adanya transisi energi. Tahun 1990-an rasio konsumsi dan produksi minyak mencapai 55\%, namun pada tahun 2004 rasio ini telah mencapai sekitar 92\% (Triatmojo, 2013). Selanjutnya fenomena ini disebabkan tingkat produksi minyak Indonesia terus mengalami penurunan. Selain itu, juga disebabkan oleh tingkat konsumsi minyak sebagai sumber energi primer terus menunjukkan peningkatan 
yang lebih besar dibandingkan dengan tingkat produksi. Akibatnya, tingkat impor minyak terus mengalami peningkatan dan pada sisi lainnya ekspor terus mengalami penurunan.

Gambaran tersebut membawa paradigma baru dalam menjaga stok penyediaan energi nasional bahwa dibutuhkan peranan semua pihak untuk menciptakan berbagai sumber energi baru dan terbarukan. Hal ini dilakukan guna memenuhi kebutuhan konsumsi domestik terutama kebutuhan dalam rumah tangga. Sebagai negara agraris Indonesia mempunyai potensi yang besar dalam meyediakan bahan baku pembuatan energi terbarukan. Produk-produk dari limbah pertanian, peternakan, perikanan dan limbah lainnya dapat dimanfaatkan sebagai sumber bahan baku alternatif dalam pembuatan energi.

Salah satu teknologi tepat guna yang dapat dimanfaatkan dalam pengolahan limbah-limbah tersebut adalah teknologi biogas skala rumah tangga. Biogas memiliki peluang yang besar dalam pengembangannya. Sulawesi Tenggara, khususnya di Kabupaten Muna Barat merupakan salah satu daerah yang memiliki potensi bahan baku dalam penyediaan energi terbarukan yang bersumber dari limbah ternak sapi. Hal ini didukung oleh keunggulan komparatif Kabupaten Muna Barat dalam pengembangan usaha ternak sapi yang dapat dilihat dari adanya daya dukung lahan yang memadai dan populasi ternak yang tersebar disemua wilayah kecamatan dengan jumlah populasi ternak sapi sebanyak 23.491 ekor (BPS, 2014). Jumlah populasi ternak tersebut memiliki potensi untuk menghasilkan energi terbarukan dari limbah ternak sapi untuk mensubstitusi penggunaaan energi tidak terbarukan (minyak tanah, solar, bensin, kayu bakar) sebagai sumber energi alternatif.

Berdasarkan gambaran tersebut, maka kajian potensi energi terbarukan dari limbah sapi di Kecamatan Kusambi Kabupaten Muna Barat Provinsi Sulawesi Tenggara penting untuk dilaksanakan.

\section{MATERI DAN METODE}

\section{Tempat dan Waktu Penelitian}

Penelitian ini dilaksanakan di Kecamatan Kusambi Kabupaten Muna Barat, pada bulan Maret sampai April tahun 2016

\section{Populasi dan Teknik Penentuan Sampel}

Populasi dalam penelitian ini adalah peternak sapi yang berada di Kecamatan Kusambi Kabupaten Muna Barat. Sementara itu, teknik penentuan sampel dalam penelitian ini dilakukan secara purposive sampling, yakni memilih siapa saja yang melakukan pengembalaan sapi secara rutin, yang memenuhi syarat untuk dijadikan sampel dengan pertimbangan bahwa responden tersebut melakukan pengembalaan sapi secara rutin, Sugiyono (2012).

\section{Variabel yang diamati}

Variabel yang akan diteliti dalam

penelitian ini adalah sebagai berikut:

- Karakteristik responden, meliputi: umur responden, jumlah tanggungan keluarga, dan lama pendidikan formal dan nonformal.

- Jumlah populasi ternak sapi

- Pemanfaatan limbah ternak

- Potensi bahan baku biogas asal ternak

- Jumlah limbah ternak yang dihasilkan peternak

- Jumlah potensi energy terbarukan

Berdasarkan hasil verfikasi lapangan, maka dipilih jumlah responden 
sebanyak 73 kepala keluarga (KK) dengan rincian sebagai berikut:

Tabel 1. Jumlah Responden di Lokasi Penelitian

\begin{tabular}{clc}
\hline No & Desa/ Kelurahan & $\begin{array}{c}\text { Jumlah } \\
\text { Responden } \\
(\text { KK) }\end{array}$ \\
\hline 1 & Konawe & 9 \\
2 & Kusambi & 8 \\
3 & Sidamangura & 10 \\
4 & Tanjung & 6 \\
5 & Pinang & 6 \\
6 & Lakawoghe & 9 \\
7 & Guali & 6 \\
8 & Lapokainse & 7 \\
9 & Kasakamu & 6 \\
10 & Lemoambo & 6 \\
& Bhakeramba & 73 \\
\hline
\end{tabular}

\section{HASIL DAN PEMBAHASAN Gambaran Umum Wilayah}

Desa Kusambi merupakan desa dengan wilayah terluas yaitu $30,08 \mathrm{~km} 2$ atau sekitar 29,11 persen dari Kecamatan Kusambi terdiri dari wilayah daratan dan lautan karena terletak di pesisir Pantai Selat Tiworo. Luas daratan Kecamatan Kusambi sebesar 103,33 km2 atau 11,40 persen dari luas daratan Kabupaten Muna Barat. luas daratan Kecamatan Kusambi. Sedangkan Desa Lapokainse dan Desa Kasakamu merupakan dua desa yang memiliki luas wilayah terkecil di Kecamatan Kusambi yaitu masingmasing hanya sekitar 2,47 persen dan 3,58 persen dari luas daratan Kecamatan Kusambi. Desa Kusambi merupakan Ibukota Kecamatan Kusambi. Desa yang jaraknya paling jauh dengan ibukota kecamatan yaitu desa Lemoambo yang berjarak 12,00 km. (BPS Kab Muna, 2015)

Kepemilikkan Ternak Sapi
Tingkat kepemilikan ternak sapi oleh peternak merupakan modal yang sangat penting dalam pengembangan populasi ternak sapi dan meningkatkan pendapatan tambahan, yang pada akhirnya juga akan mampu meningkatkan kesejahteraan peternak. Gambaran mengenai skala kepemilikan ternak di Kecamatan Kusambi Kabupaten Muna Barat dapat dilihat pada Tabel 2.

Tabel 2 menunjukkan bahwa jumlah kepemilikan ternak sapi terbanyak oleh responden di Kecamatan Kusambi terletak pada Desa Lemoambo dengan jumlah sebesar 111 ekor yang terdiri dari sapi jantan sebanyak 39 ekor dan sapi betina sebanyak 72 ekor. Sementara itu jumlah ternak terkecil oleh responden di Kecamatan Kusambi terletak di Desa Bhakeramba dengan jumlah kepemilikan ternak sapi sebesar 25 ekor yang terdiri dari sapi jantan sebanyak 12 ekor dan sapi betina sebanyak 13 ekor. Dari Tabel 2 juga diperoleh informasi bahwa total kepemilikkan ternak oleh responden di Kecamatan Kusambi adalah sebesar 508 ekor yang terdiri dari 216 ekor sapi jantan dan 292 ekor sapi betina.

Jika dilihat dari segi jumlah anakan sapi jantan, maka dapat diketahui bahwa jumlah kepemilikkan ternak terbesar juga terletak di Desa Lemoambo dan Desa Sidamangura dengan jumlah masing-masing sebanyak 11 ekor. Sementara itu kepemilikkan anakan ternak sapi dengan jumlah terkecil adalah di Desa Bhakeramba sebanyak 3 ekor. Untuk ternak sapi remaja dan dewasa diketahui bahwa ternyata di Desa Lemoambo masih merupakan daerah terbesar dari segi kepemilikkan ternak dengan jumlah sebanyak 12 ekor untuk sapi remaja dan 16 ekor untuk sapi dewasa 
Tabel 2. Jumlah Kepemilikan Ternak Sapi Oleh Respoden Kecamatan Kusambi Tahun 2016

\begin{tabular}{|c|c|c|c|c|c|c|c|c|c|c|}
\hline \multirow{3}{*}{ No } & \multirow{3}{*}{ Desa/ Kelurahan } & \multicolumn{6}{|c|}{ Kepemilikan Ternak Sapi } & \multicolumn{2}{|c|}{ Jumlah } & \multirow{3}{*}{ Total } \\
\hline & & \multicolumn{3}{|c|}{ Jantan (J) } & \multicolumn{3}{|c|}{ Betina (B) } & \multirow{2}{*}{$\mathbf{J}$} & \multirow{2}{*}{ B } & \\
\hline & & $A$ & $R$ & $D$ & $A$ & $R$ & $D$ & & & \\
\hline 1 & Kusambi & 7 & 1 & 10 & 6 & 13 & 13 & 18 & 32 & 50 \\
\hline 2 & Konawe & 7 & 5 & 10 & 1 & 13 & 9 & 22 & 23 & 45 \\
\hline 3 & Sidamangura & 11 & 9 & 10 & 3 & 13 & 16 & 30 & 32 & 62 \\
\hline 4 & Guali & 6 & 7 & 10 & 3 & 5 & 21 & 23 & 29 & 52 \\
\hline 5 & Lapokainse & 4 & 4 & 5 & 4 & 2 & 14 & 13 & 20 & 33 \\
\hline 6 & Kasakamu & 5 & 3 & 8 & 4 & 5 & 10 & 16 & 19 & 35 \\
\hline 7 & Lakawoghe & 8 & 5 & 10 & 4 & 9 & 15 & 23 & 28 & 51 \\
\hline 8 & Bhakeramba & 3 & 4 & 5 & 0 & 2 & 11 & 12 & 13 & 25 \\
\hline 9 & Lemoambo & 11 & 12 & 16 & 15 & 26 & 31 & 39 & 72 & 111 \\
\hline \multirow[t]{2}{*}{10} & Tanjung Pinang & 6 & 6 & 8 & 3 & 4 & 17 & 20 & 24 & 44 \\
\hline & Total & 68 & 56 & 92 & 43 & 92 & 157 & 216 & 292 & 508 \\
\hline
\end{tabular}

Sumber: Data Primer, Diolah (2016)

Keterangan:

$$
\begin{aligned}
& A=\text { Anak } \\
& R=\text { Remaja } \\
& D=\text { Dewasa }
\end{aligned}
$$

Selain itu, dari Tabel 5 juga diperoleh informasi bahwa jumlah kepemilikkan ternak sapi remaja dan dewasa terkecil adalah masing-masing terletak di Desa Kusambi (1 ekor sapi remaja) serta Desa Lapokainse dan Bhakeramba (5 ekor ternak sapi dewasa).

Sementara jika dilihat dari segi jumlah anakan sapi betina, maka dapat diketahui bahwa jumlah kepemilikkan ternak terbesar hanya terdapat di Desa Lemoambo dengan jumlah sebanyak 15 ekor. Sedangkan kepemilikkan anakan ternak sapi dengan jumlah terkecil terdapat di Kelurahan Konawe sebanyak 1 ekor. Dan kepemilikkan responden untuk ternak sapi remaja dan dewasa diketahui bahwa ternyata di Desa Lemoambo masih merupakan daerah terbesar dari segi kepemilikkan ternak dengan jumlah sebanyak 26 ekor untuk sapi remaja dan 31 ekor untuk sapi

dewasa. Selain itu, dari Tabel 5 diperoleh informasi bahwa jumlah kepemilikkan ternak sapi remaja dan dewasa terkecil adalah masing-masing terletak di Desa Lapokainse dan Desa Bhakeramba (2 ekor sapi remaja) serta Kelurahan Konawe (9 ekor ternak sapi dewasa).

\section{Pemanfaatan Limbah Ternak Sapi}

Pemanfaatan limbah sapi menjadi pupuk organik merupakan peluang untuk meningkatkan pendapatan petani/peternak dan perbaikan lahan pertanian yang telah rusak oleh penggunaan pupuk kimia secara terus menerus. Sejalan dengan itu peluang tersebut mengalami banyak rintangan, untuk itu perlu adanya konsep yang mampu mengubah pola pikir peternak bahwa feces dan urine yang dihasilkan ternak mereka adalah sumber tambahan pendapatan apabila diolah lebih lanjut (Rizal dan Syahdar, 2012) 
Hasil penelitian menunjukan bahwa seluruh responden (100\%) di Kecamatan Kusambi belum memanfaatkan limbah kotoran ternak sapi (feses) dalam bentuk apapun. Berdasarkan hasil pengamatan lapangan diperoleh informasi bahwa belum termanfaatkannya kotoran ternak tersebut disebabkan oleh factor ketidak pahaman terhadap kemanfaatan kotoran ternak. Selain itu kondisi tersebut juga diduga dapat disebabkan oleh rendahnya sumber daya manusia peternak.

Hasil penelitian ini berbeda dengan hasil penelitian yang dilakukan oleh Rizal dan Syahdar, (2012) yang melakukan kajian mengenai pengelolaan limbah ternak pada kawasan budidaya ternak sapi potong di Kabupaten Majalengka. Hasil penelitian menunjukkan bahwa sebagian besar responden sebanyak 69,07\% menyatakan sering melaksanakan pengumpulan limbah ternak. Menurut narasumber ada dua cara yang paling sering digunakan dalam pengumpulan limbah ternak yaitub dengan cara menyapu atau mendorong/menarik limbah dengan sekop atau alat lain (scraping) dan dengan menggunakan air untuk mengangkut limbah tersebut dalam bentuk cair (flushing).

Selanjutnya sebagian besar responden sebanyak $57,73 \%$ menyatakan kadang-kadang dan sebanyak 36,08\% menyatakan sering melaksanakan pengangkutan limbah ternak. Peternak biasanya mengangkut limbah ternak yang sudah cukup kering untuk dimanfaatkan sebagai pupuk kandang ke sawah atau kebun dengan menggunakan karung atau carangka/dingkul (alat pikulan). Selain dengan cara tersebut ada pula peternak yang langsung mengalirkan limbah ternaknya ke sawah atau kebun dengan menggunakan selang dan pompa air

\section{Potensi Energi Terbarukan Dari Limbah Ternak Sapi}

Potensi energi terbarukan yang bersumber dari limbah ternak sapi yang dimaksud dalam penelitian ini adalah potensi pemanfaatan kotoran ternak (feses) sebagai Biogas. Biogas adalah energi yang dihasilkan dari bahan organik yang terbarukan. Sumbernya bisa berasal dari kotoran hewan, tumbuhan, atau bioetanol. Bioenergi dapat menghasilkan energi listrik atau bahkan sebagai alternatif bahan bakar fosil. Energi yang dihasilkan dari bioenergi bersifat terbarukan yang ramah lingkungan. Dalam melakukan analisis dan untuk menghitung besarnya potensi energi terbarukan dari limbah ternak sapi maka perlu diketahui jumlah kepemilikan ternak sapi yang dipelihara oleh responden secara semi intensif, karena dilokasi penelitian belum tersediannya kandang yang memadai.

Pengembangan biogas yang berbasis pada peternakan dapat memberikan nilai tambah bagi peternak. Selama ini peternak hanya mengandalkan pada daging dan anakan sebagai sumber pendapatan dari usaha peternakan. Pemanfaatan kotoran ternak untuk pengembangan biogas, dapat mengurangi biaya rumah tangga peternak yaitu biaya kebutuhan energy (Aku, dkk., 2015). Data bahan baku energi Terbarukan dari Limbah Ternak Sapi di Kecamatan Kusambi Kabupaten Muna Barat disajian pada Tabel 3.

Berdasarkan data olahan dengan mengacu pada populasi ternak sapi yang ada di Kecamatan Kusambi, diperoleh potensi biogas berbahan baku limbah ternak sapi sebesar 5,080.00 Kg feses/hari 
Tabel 3. Produksi Feses, Potensi Gas dan Methan di Kecamatan Kusambi Kabupaten Muna Barat (2016)

\begin{tabular}{|c|c|c|c|c|}
\hline \multirow[t]{2}{*}{ No } & \multirow[t]{2}{*}{ Desa/Kelurahan } & $\begin{array}{l}\text { Produksi Limbah } \\
\text { (kg/hari) }\end{array}$ & $\begin{array}{l}\text { Potensi Gas } \\
\left(\mathrm{m}^{3} / \mathrm{kg}\right)\end{array}$ & \multirow[t]{2}{*}{ Methan $\left(\mathrm{M}^{3}\right)$} \\
\hline & & Sapi & Sapi & \\
\hline 1 & Kusambi & 500.00 & $9,708.74$ & $6,796.11$ \\
\hline 2 & Konawe & 450.00 & $8,737.86$ & $6,116.50$ \\
\hline 3 & Sidamangura & 620.00 & $12,038.83$ & $8,427.18$ \\
\hline 4 & Guali & 520.00 & $10,097.09$ & $7,067.96$ \\
\hline 5 & Lapokainse & 330.50 & $6,407.77$ & $4,485.44$ \\
\hline 6 & Kasakamu & 350.00 & $6,796.12$ & $4,757.28$ \\
\hline 7 & Lakawoghe & 510.00 & $9,902.91$ & $6,932.04$ \\
\hline 8 & Bhakeramba & 250.00 & $4,854.37$ & $3,398.06$ \\
\hline 9 & Lemoambo & $1,1120.00$ & $21,553.40$ & $15,087.38$ \\
\hline 10 & Tanjung Pinang & 440.00 & $8,543.69$ & $5,980.58$ \\
\hline & Jumlah & $5,080.00$ & $98,640,78$ & $69,048.54$ \\
\hline
\end{tabular}

Sumber : Data Primer, Diolah (2016)

atau setara dengan $98,640,78 \mathrm{M}^{3}$ gas dengan kanduangan methan sebesar 69,048.54 $\mathrm{M}^{3}$. Salundik (2008) menyatakan bahwa setiap $1 \mathrm{M}^{3}$ gas methan setara dengan $0.46 \mathrm{Kg}$ elpiji, 0.62 liter minyak tanah, 0.52 liter solar, 0.80 liter bensin dan $3.50 \mathrm{~kg}$ kayu bakar. Dengan demikian limbah ternak sapi yang dihasilkan di Kecamatan Kusambi setara dengan 31,762.33 Kg elpiji, setara dengan 42,810.09 liter minyak tanah, 35,905.24 liter solar, 55,238.83 liter bensin dan setara dengan 241,669.88 Kg kayu bakar.

Sekalipun demikian potensi bahan baku yang demikian besar untuk energi alternatif terbarukan (biogas) sebagai pengganti bahan bakar minyak (bbm), menurut Aku, dkk potensi tersebut belum termanfaatkan karena disebabakan oleh:

a. Sistem pemeliharaan ternak yang ekstensif sehingga feses terbuang percuma b. Instalasi biogas baik beton, fiber maupun plastik belum ada yang terbangun.

c. Instalasi biogas yang terbangun kurang memenuhi standar sehingga mudah rusak dan tidak termanfaatkan.

Peraturan menteri ESDM No 10 tahun 2015 tentang petunjuk teknis penggunaan Dana Alokasi Khusus Bidang energi Perdesaan Tahun 2015, menjelaskan bahwa untuk skala rumah tanggah dengan ukuran Kedalam 1,5 M, dengan diameter $1.50 \mathrm{M}$, maka diperoleh isi kontainer Biogas $612.30 \mathrm{Kg}$ (air dan feses), dengan perbandingan $1: 1$, maka setiap container skala rumah tangga membutuhkan lebih kurang $306.15 \mathrm{Kg}$ feses.

Dengan mengacu pada angka potensi energi alternatif berbahan baku limbah ternak, maka di Kecamatan Kusambi dapat terbangun biogas beton skala rumah tangga sebanyak 17 Unit. Tabel 4 menggambarkan sebaran potensi 
Tabel 4. Sebaran Potensi Pembangunan Instalasi Biogas Beton Skala Rumah Tangga sesuai Peraturan menteri ESDM No 10 tahun 2015

\begin{tabular}{|c|c|c|c|c|c|c|}
\hline No & $\begin{array}{c}\text { Desa/ } \\
\text { Kelurahan }\end{array}$ & $\begin{array}{c}\text { Jumlah } \\
\text { Ternak Sapi } \\
\text { (Desa/ }\end{array}$ & $\begin{array}{c}\text { Produksi } \\
\text { Limbah } \\
\text { (kg/hari) }\end{array}$ & $\begin{array}{c}\text { Potensi } \\
\text { Gas } \\
\left(\mathrm{m}^{3} / \mathrm{kg}\right)\end{array}$ & \multirow[t]{2}{*}{$\begin{array}{c}\text { Methan } \\
\left(\mathrm{m}^{3}\right)\end{array}$} & \multirow[t]{2}{*}{$\begin{array}{c}\text { Instala } \\
\text { si } \\
\text { Biogas }\end{array}$} \\
\hline & & Kelurahan) & Sapi & Sapi & & \\
\hline 1 & Kusambi & 50 & 500.00 & $9,708.74$ & $6,796.11$ & 2 \\
\hline 2 & Konawe & 45 & 450.00 & $8,737.86$ & $6,116.50$ & 2 \\
\hline 3 & Sidamangura & 62 & 620.00 & $12,038.83$ & $8,427.18$ & 2 \\
\hline 4 & Guali & 52 & 520.00 & $10,097.09$ & $7,067.96$ & 2 \\
\hline 5 & Lapokainse & 33 & 330.00 & $6,407.77$ & $4,485.44$ & 1 \\
\hline 6 & Kasakamu & 35 & 350.00 & $6,796.12$ & $4,757.28$ & 1 \\
\hline 7 & Lakawoghe & 51 & 510.00 & $9,902.91$ & $6,932.04$ & 2 \\
\hline 8 & Bhakeramba & 25 & 250.00 & $4,854.37$ & $3,398.06$ & 1 \\
\hline 9 & Lemoambo & 111 & $1,110.00$ & $21,553.40$ & $15,087.38$ & 4 \\
\hline 10 & T. Pinang & 44 & 440.00 & $8,543.69$ & $5,980.58$ & 1 \\
\hline & Jumlah & 508 & $5,080.00$ & $98,640.78$ & $69,048.54$ & 17 \\
\hline
\end{tabular}

Sumber : Data Primer, Diolah (2016)

instalasi biogas sebagai energi terbarukan yang dapat dibangun di Kecamatan Kusambi Kabupaten Muna Barat.

Sarana dan prasarana merupakan salah satu aspek penunjang dalam mendukung aplikasi biogas di Kecamatan Kusambi Kabupaten Muna Barat. Dalam penelitian ini diperoleh informasi bahwa seluruh responden yang ditemui memiliki kondisi sarana dan prasarana dalam system pemeliharaan ternak yang semi intensif.

\section{KESIMPULAN}

Berdasarkan hasil penelitian tersebut maka penulis menyimpulkan:

a. Limbah ternak sapi (feses) yang ada di Kecamatan Kusambi Kabupaten Muna Barat belum termanfaatkan karena kurangnya pengetahuan yang dimiliki oleh peternak tersebut untuk pemanfaatan limbah ternak sapi sebagai pupuk kompos/pupuk organik.

b. Potensi energi terbarukan dari limbah ternak sapi sebesar $8,890.00 \quad \mathrm{Kg}$

feses/hari atau setara dengan $172,621.36 \mathrm{M}^{3}$ gas dengan kandungan methan sebesar $120,834.95 \mathrm{M}^{3}$.

\section{DAFTAR PUSTAKA}

Aku, S.A., N., Sandiah, MA., Pagala, D., Zulkarnain, dan W. Ahmad. 2015. Penyusunan Data Base Pemanfaatan Limbah Ternak Sebagai Sumber Energi Terbarukan Di Sulawesi Tenggara, Kendari.

Badan Pusat Statistik. 2014. Statistik Sulawesi Tenggara Dalam Angka. Kendari.

Badan Pusat Statistik. 2015. Statistik Kusambi Dalam Angka, Muna

Rizal, M., B. Syahdar., 2007. Strategi Pemanfaatan Limbah Trenak SapiSebagai Solusi Peningkatan Kesejahteraan Petani di Kabupaten Maros. Fakultas Peternakan Unhas, Makasar. 
Salundik. 2008. Biogas Teori: Materi Magang Biogas. IPB. Bogor

Sugiyono. 2012. Metode Penelitian

Kombinasi (Mixed Methods).

Alfabeta. Bandung. 